\title{
Spinal radiosurgery - efficacy and safety after prior conventional radiotherapy
}

\author{
Katharina Nikolajek', Markus Kufeld ${ }^{2}$, Alexander Muacevic ${ }^{2}$, Berndt Wowra ${ }^{2}$, Maximilian Niyazi ${ }^{1}$ and \\ Ute Ganswindt ${ }^{*}$
}

\begin{abstract}
Background: Conventional external beam radiotherapy is a standard procedure for treatment of spinal metastases. In case of progression spinal cord tolerance limits further radiotherapy in pre-irradiated areas. Spinal stereotactic radiotherapy is a non-invasive option to re-treat pre-irradiated patients. Nevertheless, spinal radiosurgery results in relevant dose deposition within the myelon with potential toxicity. Aim of the study was to retrospectively analyse the efficacy and feasibility for salvage radiosurgery of spinal metastases.
\end{abstract}

Methods: During a period of 4 years (2005-2009) 70 lesions in 54 patients were treated in 60 radiosurgery sessions and retrospectively analysed. Clinical (pain, sensory and motor deficit) and radiological (CT/MRI) follow-up data were collected prospectively after radiosurgery. Pain - as main symptom - was classified by the Visual Analogue Scale (VAS) score. Every patient received single session radiosurgery after having been treated first-line with conventionally fractionated radiotherapy. Kaplan-Meier method and life tables were used to analyse freedom from local failure and overall survival.

Results: At a median follow-up of 14.5 months the actuarial rates of freedom from local failure at 6/12/18 months were $93 \%, 88 \%$ and $85 \%$, respectively. The median radiosurgery dose was $1 \times 18$ Gy (range 10-28 Gy) to the median 70\% isodose. The VAS score of patients with pain (median 6) dropped significantly (median 4, $p=0.002$ ). In 6 out of 7 patients worse sensory or motor deficit after SRS was caused by local or distant failures (diagnosed by CT/MRI). One patient with metastatic renal cell carcinoma developed a progressive complete paraparesis one year after the last treatment at lumbar level L3. Due to multiple surgery and radiosurgery treatments at the lumbar region and further local progression, the exact reason remained unclear. Apart from that, no CTC grade III or higher toxicity has been observed.

Conclusions: By applying spinal radiosurgery relevant radiation doses can be limited to small parts of the myelon. This prevents myelopathic side effects and makes it an effective and safe treatment option for well-suited patients. Especially for previously irradiated patients with local failure or pain salvage SRS represents a valuable treatment option with high local control rates, low toxicity and significant pain reduction.

\section{Background}

Conventional radiotherapy (Figure 1a) is an evidencebased treatment to control pain, neurological symptoms and instability of spinal metastases (in general osseous metastases, partially expanded to the spinal canal, [1] or other spinal tumours). Rades et al. [2] described an infield recurrence rate up to $26 \%$ for patients with spinal metastases treated with short course radiotherapy $(1 \times 8$

\footnotetext{
* Correspondence: ute.ganswindt@med.uni-muenchen.de 'Department of Radiation Oncology, Ludwig-Maximilians-University, Campus Grosshadern, Marchioninistr. 15, 81377 München, Germany Full list of author information is available at the end of the article
}

Gy or $5 \times 4$ Gy). Patients treated with long course radiotherapy $(10 \times 3$ Gy, $15 \times 2.5$ Gy or $20 \times 2$ Gy) showed a significantly better local control.

Stereotactic radiotherapy using either single fraction treatments ("radiosurgery", Figure 1b) or hypo-fractionated approaches is an established treatment option for a variety of malignant and non-malignant conditions including lung cancer, metastases and CNS tumours [3-9]. The development of modern techniques including intensity modulated radiotherapy (IMRT), small multi-leaf collimators (MLC), precise fixation systems and optimized dose calculations, increase the accuracy and fidelity of radiosurgery and

\section{Biomed Central}



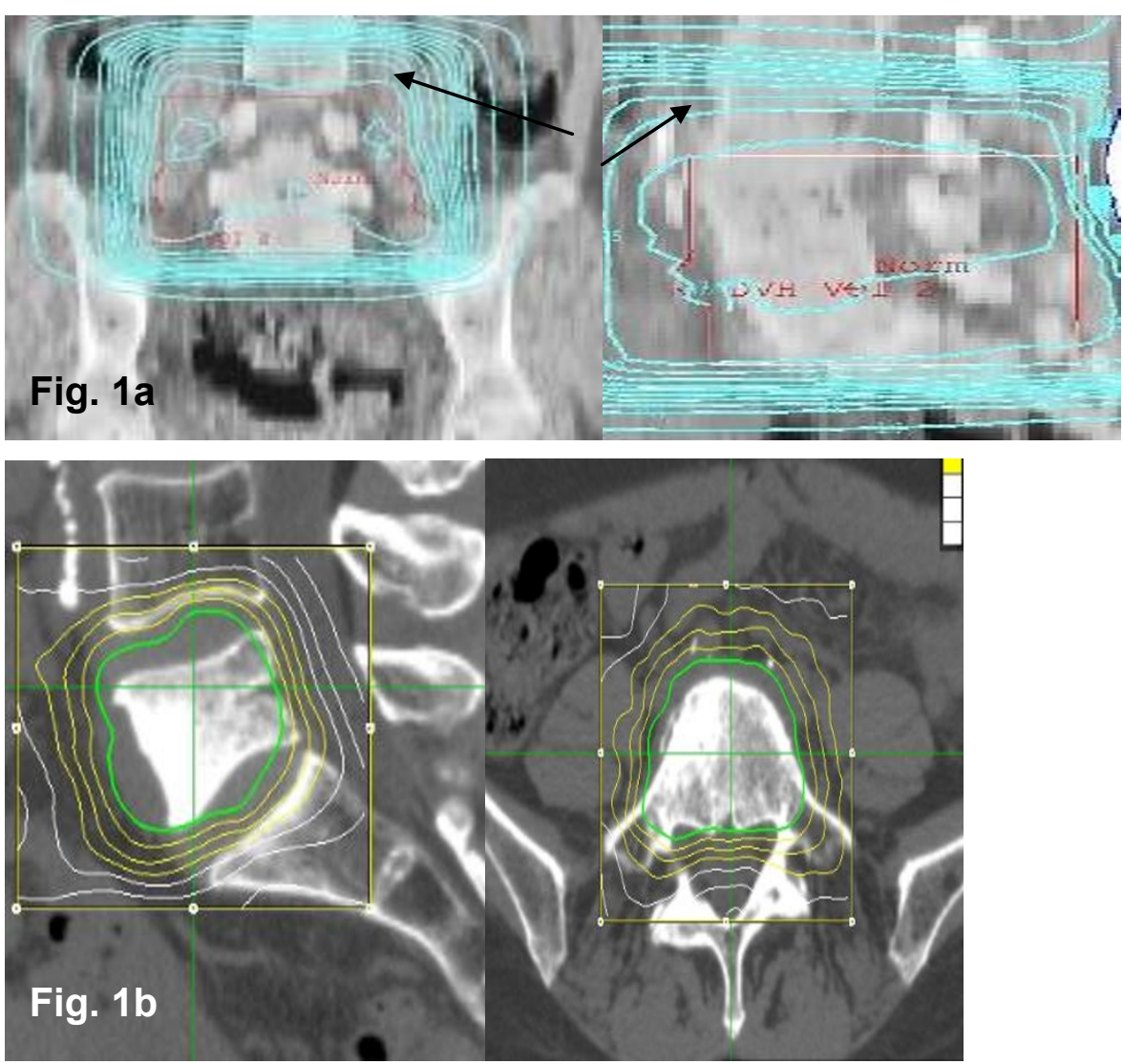

Figure 1 3-D planning in a patient with osseous metastasis in the lumbar vertebral body 5. PTV for conventional radiotherapy (Figure 1a) included L4-L1 ( $\rightarrow=$ encompassing 95\%-isodose). Below (Figure 1b) salvage SRS planning in the same patient at lumbar vertebral body 5 after conventional radiotherapy (green: 70\%-isodose, yellow: 60\%/50\%/40\%-isodose, white: 30\%/20\%-isodose). Abbreviation: SRS = spinal radiosurgery.

stereotactic radiotherapy [10-14]. In most situations stereotactic radiotherapy is used for either small volume lesions, small volume recurrences after prior radiotherapy or as boost-radiotherapy in the initial management of tumours $[8,9,15]$.

In this regard, spinal radiosurgery (SRS) has proved to be an important and convenient option in the treatment of spinal metastases for properly selected patients [16-19]. For example, SRS is not recommended in patients with a spinal cord canal compromise $>25 \%$, significant or progressive neurological deficit or spine instability [20]. Moreover the current ASTRO guidelines for the palliative treatment of bone metastases [21] clearly recommend conventional radiotherapy primarily for the treatment of pain and/or prevention of the morbidity caused by bone metastases.

In case of progression or local relapse spinal cord tolerance often limits further radiotherapy in previously irradiated areas. For patients without surgical options SRS offers a possibility to treat previously irradiated regions. Stereotactic radiotherapy of the spine reduces the radiation exposure to the spinal cord and therefore potential neurological deficiency. The aim of this study was to retrospectively analyse the clinical outcome for radiosurgery of spinal metastases in previously irradiated patients.

\section{Methods}

During a period of 4 years (2005-2009) 70 lesions were treated with SRS (CyberKnife ${ }^{\mathbb{R}}$ ) in 54 patients (32 male, 22 female). All patients had either clinical (pain or neurological) symptoms or radiological (CT/MRI) progress in the area or in the boundary area of the previously irradiated fields.

The pre-irradiation treatment parameters were documented systematically (date, target volume, daily dose, total dose, dose to the spinal cord and CT-planning data as far as available).

For SRS treatment CyberKnife ${ }^{\circledR}$ system and the skeletal structure tracking software (Xsight) were used. Patients received planning CT-scans in supine position with 1.0 $\mathrm{mm}$ slice thickness. MRI scans were fused with the planning CT images to augment soft tissue discrimination. The planning target volume (PTV) was generated using 
the gross tumour volume (GTV) without any intended margin. However, a certain margin resulted since the surrounding isodose was calculated to extend maximal $5 \mathrm{~mm}$ towards the vertebral body and 0-2 $\mathrm{mm}$ towards the spinal cord (Figure 1b). In some cases PET-scans were employed to differentiate between necrotic and relapsed tumour.

The selected SRS single fraction dose depended on actual tumour size, the proximity of the tumour to critical structures - especially the myelon - and previous irradiation dose and fields. The generally intended prescription dose was 20 Gy calculated to the $70 \%$ isodose. However, as mentioned above, depending on either some risk factors or characteristics of PTV coverage this dose prescription was adapted individually. Moreover, the maximum dose to the spinal cord was basically intended not to exceed 8 Gy.

For treatment delivery the patients were freely placed on the treatment couch in the same position as during planning CT-scan. The bone position was verified by orthogonal X-ray images. Analgesic or sedative medication was given if required.

The radiological follow up was performed with CT or MRI imaging at 3-months-intervals and documented prospectively. Using the RECIST criteria "stable disease" and "partial or complete remission" were defined as local control, whereas "progressive disease" was defined as local failure. Additional clinical follow up at 3-months-intervals included neurological examination and a standardized asking procedure for pain. Pain as a main symptom was classified by using the VAS score. Apart from this prospective evaluation of clinical outcome data the irradiation treatment parameters of both conventional and stereotactic radiotherapy were collected and analysed retrospectively.

\section{Statistical Analysis}

The Stata/IC 10.1 software (Stata Corp., College Station, Texas, USA) was used for statistical analysis. KaplanMeier method and life tables were calculated to analyse overall survival and freedom from local failure. We used the log-rank test to analyse the outcome for patient characteristics (sex, age, Karnofsky performance status scale), tumour characteristics (primary tumour, quantity of treated spinal lesions) and treatment-related variables (single/ total dose of conventional pre-irradiation, radiosurgery dose, > 8-Gy-volume to the dural sac, time interval conventional radiotherapy to SRS). We used the t-test to analyse VAS score as a classification for pain.

\section{Results}

70 lesions in 54 patients ( 32 male, 22 female) with different primary tumour sites (sarcoma, CNS, chordoma, renal, lung, breast, prostate, colorectal, gynaecological, melanoma and others) were treated in 60 radiosurgery sessions. Out of these 54 patients, 13 had progressive disease at the primary spinal/paraspinal tumour site, whereas 41 patients suffered from metastatic disease. Within the 41 metastatic patients most common lesions were caused by renal cell carcinoma $(\mathrm{n}=10 ; 18.5 \%)$ and non-small-cell lung cancer $(\mathrm{n}=7 ; 13 \%) .14$ lesions in 13 patients were located intraspinal/-dural, while 56 lesions represented osseous or paraspinal lesions. In addition, 26 patients had undergone at least secondary surgery and 30 patients had received chemotherapy before radiosurgical treatment.

All spinal regions, but most frequently thoracic and lumbar lesions, were affected. Detailed patient and characteristics are shown in table 1.

All 70 lesions were located in conventionally pre-irradiated volumes. In 47 patients the prior conventional radiotherapy (range of daily doses $1.6-3 \mathrm{~Gy}, 1$ patient $1 \times$ 8 Gy) decidedly covered parts of the vertebral column/ spinal cord (but also 1 patient with whole body irradiation, 2 patients with irradiation of entire craniospinal axis, all other patients $\geq 3$ vertebral bodies), whereas 7 patients had been treated in the course of curative intended 3Dplannings (mediastinal, paraaortic, paraspinal region) with partial dose deposition to the spinal cord (single doses 1.8 - 2 Gy). Based on the available documents of prior radiotherapy, we re-calculated the maximum total dose applied to the myelon for the whole cohort using the linear-quadratic model $(\alpha / \beta=2$, daily dose 2 Gy). Thus the median re-calculated nBED Gy $2 / 2$ to the spinal cord was 42.8 Gy (mean $41.5 \mathrm{~Gy}$, range 18 - $48.7 \mathrm{~Gy}$ ).

32 of 54 patients suffered from significant pain before SRS (median VAS score 6). 14 patients suffered from complete or incomplete paresis, 12 patients suffered from par-/hypaesthesia and 5 patients had both motor and sensory deficits before SRS treatment.

The median time to SRS re-treatment was 15 months (95\% C.I. 14-27 months).

The median encompassing dose applied by SRS was 18 Gy (range 10-28 Gy) to the median 70\%-isodose. Additionally the median tumour volume was $17.6 \mathrm{cc}$ (mean $26.3 \mathrm{cc}$, range $0.2-134 \mathrm{cc}$ ), the median $>8$-Gy-volume to the dural sac was $0.74 \mathrm{cc}$ (mean $1.4 \mathrm{cc}$, range $0-9 \mathrm{cc}$ ). With the exception of two patients, who were treated with re-radiosurgery at the same lumbar level (L3, but contralateral vertebral body involvement) all metachronously treated lesions were distant. Detailed SRS treatment parameters are shown in table 2 .

At a median follow up of 14.5 months (range 3-48 months) we observed 9 (12.9\%) local failures (7 "in-field" and 2 "field-margin" relapses, $10 \%$ and $2.9 \%$, respectively) within the 70 treated lesions. The actuarial rates of freedom from local failure at 6/12/18 months were 93\%/88\%/ $85 \%$ (Figure 2). As a result in the subgroup of patients with local failure after SRS we observed significant larger 
Table 1 Patient, tumour and treatment characteristics for all patients

\begin{tabular}{|c|c|c|}
\hline Characteristic & \multicolumn{2}{|c|}{ Value } \\
\hline Median age (years), (range) & \multicolumn{2}{|c|}{$56,(17-82)$} \\
\hline No of patients & \multicolumn{2}{|l|}{54} \\
\hline \multicolumn{3}{|l|}{ Sex } \\
\hline Male & \multicolumn{2}{|l|}{32} \\
\hline Female & \multicolumn{2}{|l|}{22} \\
\hline \multicolumn{3}{|l|}{ Karnofsky performance status scale } \\
\hline Median & \multicolumn{2}{|l|}{80} \\
\hline Range & \multicolumn{2}{|c|}{$50-100$} \\
\hline Spinal region/No. of treated lesions & & $(\%)$ \\
\hline$\underline{\text { Total of lesions in } 54 \text { patients }}$ & 70 & $(100)$ \\
\hline Patients with 1 lesion & 43 & \\
\hline Patients with 2-6 lesions & 11 & \\
\hline Cervical & 8 & $(11.4)$ \\
\hline Thoracic & 28 & $(40.0)$ \\
\hline Lumbar & 27 & (38.6) \\
\hline Sacral & 7 & $(10.0)$ \\
\hline$\underline{\text { Total of treatment sessions }}$ & 60 & \\
\hline \multicolumn{3}{|c|}{ No. of treated lesions/treatment sessions } \\
\hline 1 & \multicolumn{2}{|l|}{42} \\
\hline 2 & \multicolumn{2}{|l|}{9} \\
\hline 3 & \multicolumn{2}{|l|}{2} \\
\hline 4 & \multicolumn{2}{|l|}{1} \\
\hline Histology & $n$ & $(\%)$ \\
\hline Primary tumours & 13 & $\underline{(24.1)}$ \\
\hline Sarcoma & 5 & $(9.3)$ \\
\hline CNS & 3 & (5.6) \\
\hline Chordoma & 3 & (5.6) \\
\hline Others & 2 & $(3.7)$ \\
\hline Metastases & $\underline{41}$ & $\underline{(75.9)}$ \\
\hline Renal & 10 & (18.5) \\
\hline Lung & 7 & (13) \\
\hline Breast & 7 & (13) \\
\hline Prostate & 3 & (5.6) \\
\hline Colorectal & 2 & (3.7) \\
\hline Gynaecological & 2 & (3.7) \\
\hline Melanoma & 1 & $(1.8)$ \\
\hline Others & 7 & (13) \\
\hline
\end{tabular}

Time diagnose to SRS (years)

\begin{tabular}{ll} 
Median & 4.6 \\
Mean & 6.7 \\
Range & $0.6-29$ \\
95\% C.I. & $2.4-6.4$ \\
\hline me RTX to SRS (months) & \\
Median & 15 \\
Mean & 42 \\
Range & $1-505$ \\
95\% C.I. & $13.8-26.9$ \\
mour volume - GTV (cc) & \\
Median & 17.6 \\
Mean & 26.3
\end{tabular}

Table 1 Patient, tumour and treatment characteristics for all patients (Continued)

$\begin{array}{ll}\text { Range } & 0.2-134 \\ 95 \% \text { C.I. } & 12.2-26.2\end{array}$

Abbreviations: SRS = spinal radiosurgery; RTX = conventional radiotherapy.

tumour volumes treated by SRS $(\mathrm{p}=0.001)$. Moreover, the median time interval from conventional radiotherapy to SRS displayed a trend to be shorter in this subgroup ( $\mathrm{p}=$ 0.165). Detailed tumour and treatment characteristics of patients with local failure are shown in table 3.

For the whole cohort the median overall survival after SRS treatment were 16.2 months and 42 months after initial radiotherapy, respectively. Patients being re-

Table 2 SRS treatment parameters

\begin{tabular}{|c|c|}
\hline Parameter & Value \\
\hline \multicolumn{2}{|c|}{ Prescription dose (Gy) $70 \%$ isodose } \\
\hline Median & 18 \\
\hline Mean & 18.1 \\
\hline Range & $10-28$ \\
\hline 95\% C.I. & $17-18$ \\
\hline \multicolumn{2}{|c|}{ Dose maximum (GTV) } \\
\hline Median & 25.7 \\
\hline Mean & 26.8 \\
\hline Range & $20-43$ \\
\hline 95\% C.I. & 23.9-28.6 \\
\hline \multicolumn{2}{|c|}{ Dose minimum (GTV) } \\
\hline Median & 12.2 \\
\hline Mean & 12 \\
\hline Range & $3.8-20.3$ \\
\hline 95\% C.I. & 11.4-12.7 \\
\hline \multicolumn{2}{|c|}{ Peripheral isodose (\%) } \\
\hline Median & 70 \\
\hline Mean & 67 \\
\hline Range & $50-80$ \\
\hline 95\% C.I. & $65-70$ \\
\hline \multicolumn{2}{|c|}{ No. of beams/site or lesion } \\
\hline Median & 215 \\
\hline Mean & 207 \\
\hline Range & $64-341$ \\
\hline 95\% C.I. & $182-239$ \\
\hline \multicolumn{2}{|c|}{10 Gy irradiated volume (cc) } \\
\hline Median & 95 \\
\hline Mean & 120 \\
\hline Range & $0.6-479$ \\
\hline 95\% C.I. & $63-132$ \\
\hline \multicolumn{2}{|c|}{$>8$ Gy volume of spinal cord (cc) } \\
\hline Median & 0.74 \\
\hline Mean & 1.4 \\
\hline Range & $0-9.3$ \\
\hline 95\% C.I. & $0.4-1.2$ \\
\hline
\end{tabular}




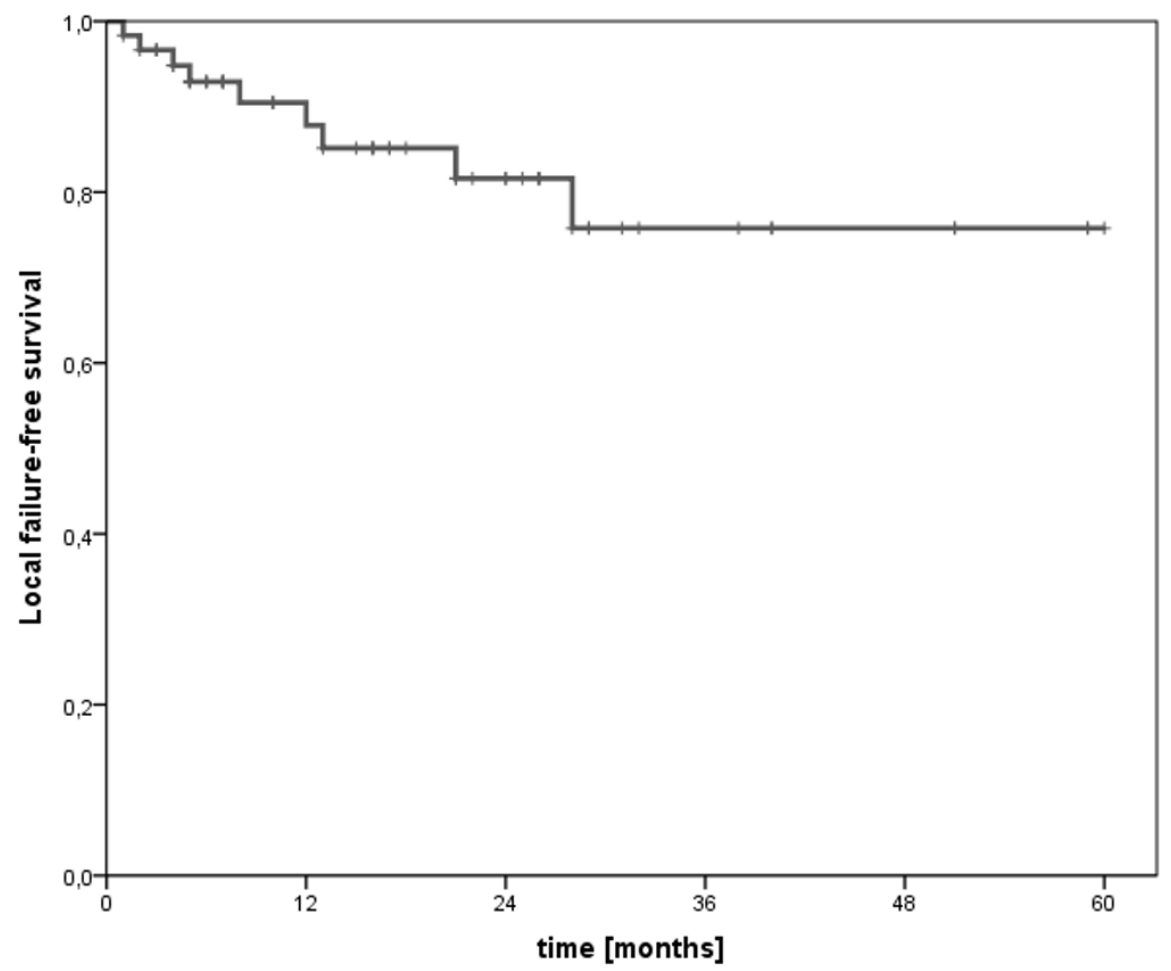

Figure $\mathbf{2}$ Local failure-free survival after salvage spinal radiosurgery.

irradiated with SRS at their initial primary tumour region had a significant better overall survival when compared with patients suffering from metastatic tumour disease $(p=0.003$, Figure 3$)$.

Among the patients with initial pain symptoms the VAS score dropped significantly within 3 months after the treatment (median VAS score $4, \mathrm{p}=0.002$ ). After SRS in 7 patients impairment of neurological symptoms was found (table 4). The exact assignment of neurological symptoms to the spinal level was not always clearly possible. One patient with renal cell carcinoma developed progressive paraparesis one year after the last treatment of a widespread spinal metastasis at lumbar level L3 (laminectomy with internal stabilization, conventional radiotherapy, 2 times stereotactic radiosurgery at different locations of L3, metachronous SRS at L2 and L4, surgery for recurrence). Due to the multiple treatments and further tumour progression in this area, the exact reason

Table 3 Tumour and treatment characteristics for patients with local failure $(n=9)$

\begin{tabular}{|c|c|c|c|c|c|c|c|}
\hline No. & $\begin{array}{l}\text { Tumour } \\
\text { type }\end{array}$ & Location & $\begin{array}{l}\text { Volume } \\
\text { (cc) }\end{array}$ & $\begin{array}{l}\text { Prescription Dose (Gy) } \\
\text { SRS }\end{array}$ & $\begin{array}{l}\text { Isodose (\%) } \\
\text { SRS }\end{array}$ & $\begin{array}{l}\text { Time (months) RTX to } \\
\text { SRS }\end{array}$ & $\begin{array}{l}\text { Prior RTX Dose nBED Gy } \\
2 / 2\end{array}$ \\
\hline 1 & $\mathrm{RCC}$ & $\mathrm{T} 11$ & 93.3 & 16 & 65 & 21.7 & 42,8 \\
\hline 2 & $\mathrm{RCC}$ & L3 & 134.2 & 19 & 55 & 8.8 & 40 \\
\hline 3 & Chordoma & L2 & 39.7 & 22 & 65 & 12.4 & 40 \\
\hline 4 & Prostate & T11 & 89.8 & 18 & 65 & 2.8 & 45 \\
\hline 5 & Melanoma & C7 & 17.7 & 17 & 65 & 4.3 & 33.6 \\
\hline 6 & Sarcoma & L4 & 56.3 & 20 & 70 & 2 & 44 \\
\hline 7 & Breast & L3 & 37.6 & 20 & 70 & 28.8 & 42.8 \\
\hline 8 & MPNST & $\mathrm{T1}$ & 26.8 & 14.5 & 70 & 5.8 & 42.8 \\
\hline \multirow[t]{4}{*}{9} & $\mathrm{RCC}$ & T9 & 49.9 & 22 & 70 & 13.9 & 42.8 \\
\hline & Median & - & 49.9 & 19 & 65 & 8.8 & 42.8 \\
\hline & Mean & - & 60.6 & 18.8 & 66 & 11.2 & 41.6 \\
\hline & Range & - & $18-134$ & $14.5-22$ & $55-70$ & $2-28.8$ & $33.6-45$ \\
\hline
\end{tabular}




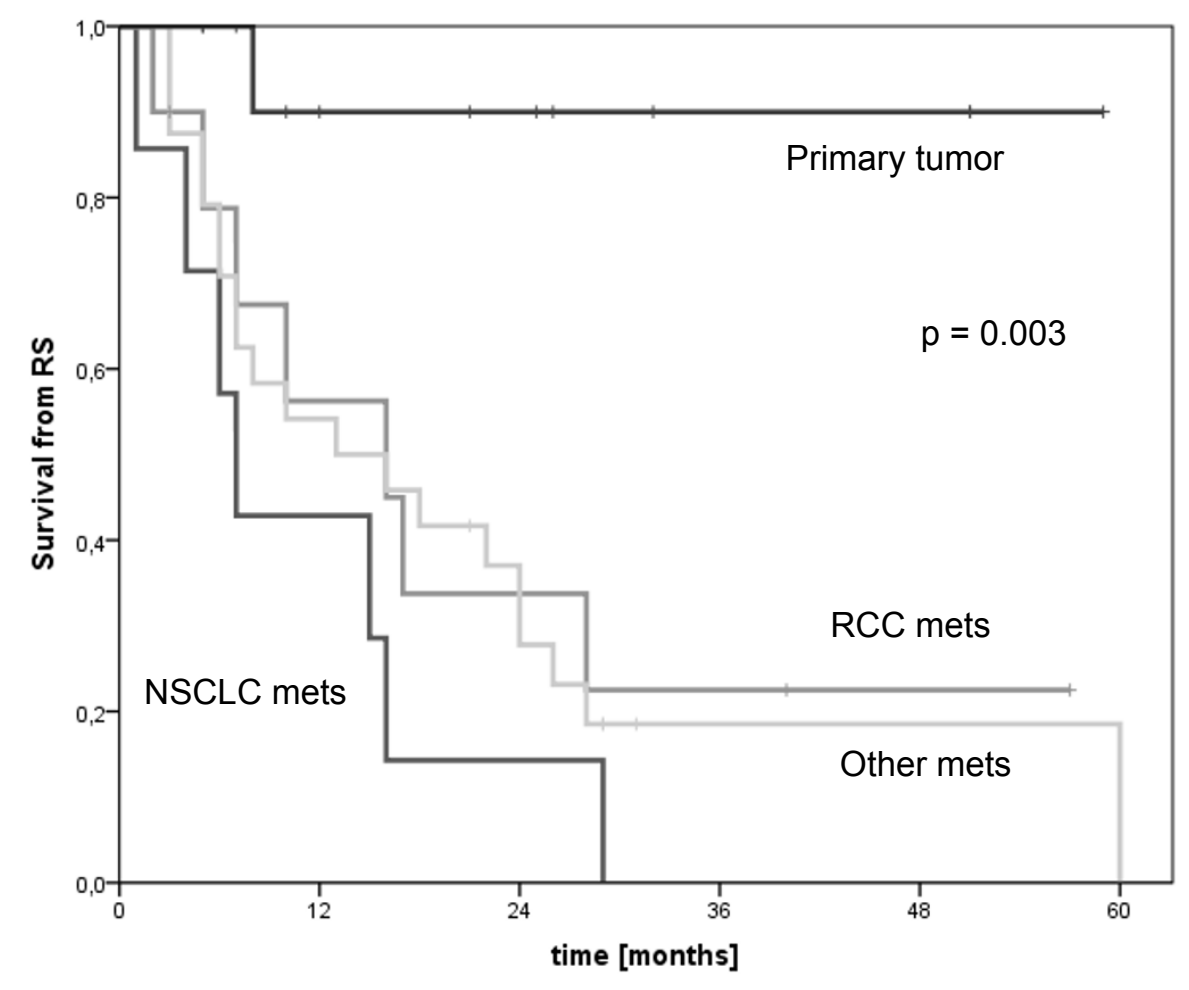

Abbreviations: $\mathrm{RS}=$ radiosurgery, mets = metastases; NSCLC $=$ non-small-cell lung cancer; $\mathrm{RCC}=$ renal call carcinoma

Figure 3 Overall survival from salvage spinal radiosurgery of most common tumour sites. Abbreviations: RS = radiosurgery, mets $=$ metastases; NSCLC = non-small-cell lung cancer; RCC = renal call carcinoma.

for paraparesis could not be identified. However, radiation induced myelopathy has to be considered due to the frequent radiosurgery treatments at different lumbar levels (patient with maximum of lesions/lesion volumes and treatment sessions in our cohort).

Apart from that, no CTC grade III or higher grade neurological or other (necrosis, bleeding) toxicities have been observed.

\section{Discussion}

Aim of our study was to analyse the clinical outcome of salvage radiosurgery for spinal tumours/metastases in previously irradiated patients in regard to efficacy (local control, pain relief, neurological symptoms) and safety (potential side effects). At a median follow up of 14.5 months our results in 54 patients with 70 treated lesions by a median SRS dose of 18 Gy (range 10-28 Gy) to the median 70\%-isodose provide evidence that single-dose application is associated with high local control rates. In regard to symptoms of pain by using the VAS score prospectively we observed a significant decrease of pain in $75 \%$ of the patients. $7 / 54$ patients developed an impairment of neurological (2/54 sensory and 5/54 motor) deficits after SRS, among them 6 patients with causally progressive local or distant failures.

By all means, stereotactic radiotherapy is an attractive way to treat spinal metastases non-invasively with encouraging results in selected patients. Although technical feasibility and growing expertise in stereotactic treatment approaches increased accuracy and fidelity of spinal SBRT and SRS [16,18-20,22-26] some important challenges on this topic still remain under discussion.

The QUANTEC data review published in 2010 estimated the risk for myelopathy $<1 \%$ and $<10 \%$ at 54 Gy and $61 \mathrm{~Gy}$, respectively, when conventional fractionation (1.8-2 Gy) is used [27]. However, in the case of singledose or hypo-fractionated radiotherapy the maximum spinal cord tolerance is quite more uncertain and sufficient long-term-data are missing [27]. Sahgal et al [28] calculated a dosimetric modelling by comparing SRS parameters in not pre-irradiated patients with myelopathy $(n=5)$ and patients without myelopathy $(n=19)$ after SRS, respectively. Based on these results they recommend a point dose threshold of $10 \mathrm{~Gy}$ for a single 
Table 4 Clinical (pain/neurological) outcome of all treatment sessions

\begin{tabular}{|c|c|}
\hline Outcome parameter & Value \\
\hline Total No. of treatment sessions & 60 \\
\hline \multicolumn{2}{|l|}{ Pain } \\
\hline VAS Score median pre-RS $(n=60)$ & 2 \\
\hline VAS Score median post-RS $(n=60)$ & 0 \\
\hline p-value pre-/post-RS $(n=60)$ & 0.07 \\
\hline Patients without initial pain pre-RS & 26 \\
\hline VAS Score median pre-RS & 0 \\
\hline Patients with pain pre-RS & 32 \\
\hline VAS Score median pre-RS & 6 \\
\hline VAS Score median post-RS & 4 \\
\hline $\mathrm{p}$-value pre-/post-RS & 0.0056 \\
\hline \multicolumn{2}{|l|}{ Sensory deficit } \\
\hline No. of patients pre-RS & 12 \\
\hline \multicolumn{2}{|l|}{$\underline{\text { Sensory deficit post-RS }}$} \\
\hline Better & 1 \\
\hline Same & 9 \\
\hline Worse & 2 \\
\hline \multicolumn{2}{|l|}{ Motor deficit } \\
\hline No. of patients pre-RS & 14 \\
\hline \multicolumn{2}{|l|}{ Motor deficit post-RS } \\
\hline Better & 1 \\
\hline Same & 8 \\
\hline Worse & 5 \\
\hline
\end{tabular}

fraction (nBED of 30 Gy 2/2) to the thecal sac. Ryu et al. [29] described a partial volume tolerance to the spinal cord of 10 Gy to $10 \%$ of the spinal cord volume defined as $6 \mathrm{~mm}$ above and below the radiosurgery target. Gibbs et al. analysed 6 cases of delayed myelopathy after SRS: A total of 1075 patients treated with radiosurgery were investigated and 6 patients developed a delayed myelopathy. Specific dosimetric parameters associated with this complication could not be identified apart from the fact that 3 of the 6 analysed patients received spinal cord doses above 8 Gy [26].

Nevertheless, the problem of cumulative spinal cord tolerance for conventional radiotherapy followed by stereotactic radiotherapy is crucial. Some recent publications also showed efficacy and safety of salvage SRS or hypo-fractionated stereotactic radiotherapy (table 5).

Sahgal et al. [30] analysed 39 patients with 60 lesions, 37 of 60 lesions had previous irradiation. Thereby a dose of 24 Gy in three fractions to the $60 \%$-isodose was used, the median $\geq 8$ Gy volume to the spinal cord/cauda equina was 0.3 (range 0-28) cc and 0.3 (range 0-17) cc, respectively. No myelopathy or radiculopathy occurred. For the salvage group the 1-year progression-free probability was $96 \%$, the median pre-irradiation total dose was 36 Gy/14 fractions. However, the median follow-up time of 7 months was rather short. There was no significant difference in regard to clinical outcomes between previously irradiated or un-irradiated patients. By comparison to our data with a median follow up of 14.5 months we observed a 1-year local control rate of $88 \%$ and the median $\geq 8$ Gy volume was 0.74 (range $0-9$ ) cc in our cohort. With regard to the pre-irradiation dose we documented a slightly higher median nBED Gy $2 / 2$ (42.8, range 18 - 48.7 Gy) to the spinal cord.

Choi et al. [31] confirmed safety and performance for SRS after prior irradiation in patients with spinal metastases as well. They reviewed 51 lesions in 42 patients with a median previous spinal cord dose of 40 Gy. SRS was delivered to a median marginal dose of 20 Gy (range 10$30 \mathrm{~Gy}$ ) in 1-5 fractions (median 2), according to a converted median equivalent single-session tumour dose of 15 Gy $(\alpha / \beta=10)$. With a median follow-up of 7 months the local control rates at $6 / 12$ months were $87 \% / 73 \%$. Median single-session equivalent spinal cord maximum doses $(\alpha / \beta$ $=3$ ) were 10.9, 13.8, 12.5, 12.1, and 12.1 Gy for 1- to 5-session SRS. One patient (2\%) experienced Grade 4 neurotoxicity; a significant pain relief was observed in $65 \%$ of the patients. Remarkably, the time to re-treatment $(\leq 12$ months) together with a single-session equivalent dose $\leq$ 15 Gy was associated with a significantly higher risk for local failure. In summary, they discuss an increased efficacy of higher single-doses in case of a short period of tumour recurrence assuming that the short time interval between irradiation and recurrence can be interpreted as more aggressive tumour growth behaviour. In this context our subgroup analysis of patients with local failure revealed a median time interval to re-treatment of 8.8 (range 2-28.8) months. However, we did not observe any differences concerning the applied SRS doses, but our results demonstrated significantly larger tumour volumes in this patient group. Bearing in mind that a longer time interval between two irradiation series to the spinal cord is assumed to be associated with a lower risk for severe late toxicity $[27,32]$, both the predictive and prognostic factor "time to re-treatment" and "tumour aggressiveness" causally increases the risk of neurological complications in such patients.

Gerszten et al. reported the largest series of 500 cases treated with single-session SRS (mean single dose 20, range 12.5-25 Gy) including 344 pre-irradiated patients [16]. At a median follow up of 21 months the long-term local control was $88 \%$ for the most common primary tumour sites (294 pre-irradiated and non-irradiated patients, see table 5). Long-term pain improvement occurred in 290 of 336 (pre-irradiated and non-irradiated) cases. The mean $<8$ Gy volume to the spinal canal was $0.6 \mathrm{cc}$ for the whole cohort. Regarding the endpoints pain and local control the authors conclude that salvage SRS for metastases is both safe and clinically effective, especially for patients with solitary sites of spine involvement. 
Table 5 Studies on spinal stereotactic re-irradiation (SBRT/SRS) after conventional radiotherapy

\begin{tabular}{|c|c|c|c|c|}
\hline Author & Gerszten et al. 2007 [16] & Sahgal et al. 2009 [30] & Choi et al. 2010 [31] & Garg et al. 2011 [25] \\
\hline No of patients & $344 / 500^{*}$ & $39^{*}$ & 42 & 59 \\
\hline No. of lesions & $\approx 344$ & $37 / 60^{*}$ & 51 & 63 \\
\hline \multicolumn{5}{|l|}{ Tumour volume (cc) } \\
\hline Mean/median (range) & $\begin{array}{c}46 / 29(0.2-264) \\
\left(n=500^{*}\right)\end{array}$ & $\begin{array}{c}-/ 21(0.4-177) \\
(n=37)\end{array}$ & $-/ 10.3(0.2-128.6)$ & $67.1 / 51.2(3.5-266)$ \\
\hline SRS/SBRT & $1 \times 12.5-25$ Gy (mean 20 Gy) & 8-30 Gy (median 24 Gy) & 10-30 Gy (median 20 Gy) & $5 \times 6$ Gy \\
\hline fractionation & & 1-5 fractions (median 3) & 1-5 fractions (median 2) & $3 \times 9 \mathrm{~Gy}$ \\
\hline Peripheral isodose & $80 \%$ & $60 \%$ & & $95 \%$ \\
\hline Follow up (months) & $\begin{array}{l}21 \text { (median) } \\
\left(\mathrm{n}=500^{*}\right)\end{array}$ & 7 (mean) & 7 (mean) & 17.6 (mean) \\
\hline \multicolumn{5}{|l|}{ Local control } \\
\hline 6 months & & & $87 \%$ & \\
\hline 12 months & & $96 \%(n=31)$ & $73 \%$ & $76 \%$ \\
\hline "long term" & $88 \%\left(n=294^{*}\right)$ & & & \\
\hline Overall survival & - & & & \\
\hline Median (months) & & 21 & & \\
\hline 6 months & & & $81 \%$ & \\
\hline 12 months & & & $68 \%$ & $76 \%$ \\
\hline 24 months & & $45 \%$ & & \\
\hline Previous RT dose & $\begin{array}{l}10 \times 3 \text { Gy or } \\
14 \times 2.5 \text { Gy }\end{array}$ & $\begin{array}{l}\text { Median } 36 \text { Gy } \\
14 \text { fractions }\end{array}$ & $\begin{array}{c}\text { Median } 40 \text { Gy } \\
2 \text { Gy dose equivalent }\end{array}$ & $\begin{array}{c}<45 \text { Gy } \\
\text { (subgroup analysis } \\
</>35 \text { Gy) }\end{array}$ \\
\hline
\end{tabular}

Abbreviations: SRS = radiosurgery; SBRT = Stereotactic body radiotherapy; ${ }^{*}$ cohort included patients with/without pre-irradiation

In 2011 Garg et al. reported a prospective evaluation of spinal re-irradiation by using SBRT $(5 \times 6$ Gy and 3 $\times 9$ Gy prescription dose, mean total dose constraint to the spinal cord 10 and 9 Gy, respectively) in 59 patients [25]. At a median follow up of 17.6 months they observed an actuarial 1-year local control rate and overall survival of both $76 \%$. The CTC and McCormick neurological function system were used to evaluate toxicity and neurological status, respectively. Freedom from neurologic deterioration from any cause was $92 \%$ at 1 year. Two patients experienced mild to moderate radiation injury (lumbar plexopathy). Based on the performed local relapse analysis the authors conclude that initial surgery should be considered for tumours within $5 \mathrm{~mm}$ of the spinal cord.

Taken together, this data provide strong evidence that salvage stereotactic radiotherapy in pre-irradiated patients can be regarded as safe and effective treatment option. Despite some limitations presented data correlate well with those from literature, especially regarding the clinical outcome in terms of local control and pain relief. Some limitations particularly result from retrospective analysis of radiotherapy treatment parameters and there should be some caution in interpreting the data. Due to the fact that previous conventional radiotherapy often had been applied without the use of 3D planning, exact dose distributions were not available in all cases. Thus we did not calculate a cumulative nBED value for the individual patient. In this context the recalculated median nBED Gy $2 / 2$ of prior conventional radiotherapy $(42.8 \mathrm{~Gy})$ in our cohort was slightly higher than reported by other groups. Moreover, reported patient collective may be rather heterogeneous including 13 non-metastatic patients with progressive primary tumour at the initial high-dose pre-irradiated tumour site. Although overall survival rate in this patient subgroup was significantly better (Figure 3 ) the 1 -year OS rate of $62 \%$ for the whole cohort is worse than reported by other series. In addition, both our percentage of intraspinal/-dural lesions (20\%) in opposition to osseous or paraspinal lesions and 14/54 patients with motor deficit prior to SRS have to be borne in mind.

Beside highly important challenges in technical conditions accompanied by increasing accuracy and fidelity of spinal SBRT a precise patient selection in regard to clinical outcome is of special importance. Special criteria have to be fulfilled like singular, small tumour volumes. In not pre-irradiated patients the best benefit of treatment is expected in patients with good clinical condition and severe tumour associated pain. As mentioned above patients with spinal cord compression more than $25 \%$ with significant or progressive neurologic deficits or spine instability should not be treated with SRS [16-20,25]. However, in patients compromised by previous irradiation 
and missing surgical options SRS offers the only effective treatment option in some clinical constellations.

The question in how far SRS may replace in future any conventional radiotherapy in metastatic patients remains under debate. Patients with spinal metastases often suffer from pain, neurological deficiency or instability of vertebral bodies. Conventional radiotherapy has been proven to be an effective option in the treatment of spinal metastases [1]. A standard fractionation schedule for conventional radiotherapy depends on individual aspects of the patient like overall prognosis or clinical symptoms. Lower daily fractions are correlated with better remineralisation and longer pain relief than short courses with high single doses, so patients with oligometastases and a good prognosis may benefit from lower daily fractions $[1,23,33]$. Accordingly, Rose et al [34] described in a recent publication a higher risk of bone fracture after first-line treating spinal metastases located between T10 and os sacrum with high single dose intensity-modulated radiotherapy.

In this context the current ASTRO guidelines for the palliative treatment of bone metastases [21] clearly state that conventional radiotherapy continues to be the mainstay for the treatment of pain and/or prevention of the morbidity caused by bone metastases. The Task Force recommended that the use of SBRT/SRS in the primary treatment setting should be limited to highly selected patients and preferably within a prospective trial.

\section{Conclusions}

Under certain technical conditions SRS is an effective and safe option to treat previously irradiated spinal metastases for properly selected patients. In cases of local failure salvage SRS reveals high local control rates with low toxicity and significant pain reduction. Even if SRS is not generally recommended for the primary treatment setting of bone metastases SRS represents a highly valuable treatment option in pre-irradiated patients.

\section{List of abbreviations}

a/ß: alpha/beta value; C: cervical vertebra; cc: cubic centimetre; CNS: central nervous system; CT: computed tomography; CTC: common toxicity criteria; GTV: gross tumour volume; Gy: Gray; IMRT: intensity modulated radiotherapy; L: lumbar vertebra; mets: metastases; MLC: multi-leaf collimator; MPNST: malignant peripheral nerve sheath tumour; MRI: magnetic resonance imaging; nBED: normalized biological effective dose; NSCLC: non-small-cell lung cancer; PFP: progression-free probability; PTV: planning target volume; QUANTEC: quantitative analyses of normal tissue effects in the clinic; RCC: renal call carcinoma; RECIST: response evaluation criteria in solid tumours; RTX: radiotherapy; S: sacral vertebra; SBRT: stereotactic body radiotherapy; SRS: spinal radiosurgery; T: thoracic vertebra; VAS: visual analogue scale.

\section{Author details}

'Department of Radiation Oncology, Ludwig-Maximilians-University, Campus Grosshadern, Marchioninistr. 15, 81377 München, Germany. ${ }^{2}$ Cyberknife Center, Max-Lebsche-Platz 31, 81377 München, Germany.

\section{Authors' contributions}

AM, BW and UG planned the study. KN, UG and MK collected and analysed the data, MK, KN and MN performed the statistics. Radiosurgery and clinical outcome data were collected by AM, BW and MK. KN prepared, KN and UG revised the manuscript. All authors read and approved the manuscript.

\section{Conflict of interest statement}

The authors declare that they have no competing interests.

Received: 22 November 2011 Accepted: 16 December 2011

Published: 16 December 2011

\section{References}

1. Arcangeli G, Giovinazzo G, Saracino B, D'Angelo L, Giannarelli D, Micheli A: Radiation therapy in the management of symptomatic bone metastases: the effect of total dose and histology on pain relief and response duration. Int I Radiat Oncol Biol Phys 1998, 42(5):1119-1126.

2. Rades D, Stalpers LJ, Veninga T, Schulte R, Hoskin PJ, Obralic N, Bajrovic A, Rudat V, Schwarz R, Hulshof MC, et al: Evaluation of five radiation schedules and prognostic factors for metastatic spinal cord compression. J Clin Oncol 2005, 23(15):3366-3375.

3. Abboud M, Haddad G, Kattar M, Aburiziq I, Geara FB: Extraneural metastases from cranial meningioma: a case report. Radiat Oncol 2009, 4:20.

4. Baba F, Shibamoto Y, Tomita N, Ikeya-Hashizume C, Oda K, Ayakawa S, Ogino H, Sugie C: Stereotactic body radiotherapy for stage I lung cancer and small lung metastasis: evaluation of an immobilization system for suppression of respiratory tumor movement and preliminary results. Radiat Oncol 2009, 4:15.

5. Hurkmans CW, Cuijpers JP, Lagerwaard FJ, Widder J, van der Heide UA, Schuring D, Senan S: Recommendations for implementing stereotactic radiotherapy in peripheral stage IA non-small cell lung cancer: report from the Quality Assurance Working Party of the randomised phase III ROSEL study. Radiat Oncol 2009, 4:1.

6. Minniti G, Amichetti M, Enrici RM: Radiotherapy and radiosurgery for benign skull base meningiomas. Radiat Oncol 2009, 4:42.

7. Oshiro Y, Aruga T, Tsuboi K, Marino K, Hara R, Sanayama Y, Itami J: Stereotactic body radiotherapy for lung tumors at the pulmonary hilum. Strahlenther Onkol 2010, 186(5):274-279.

8. Balducci M, Apicella G, Manfrida S, Mangiola A, Fiorentino A, Azario L, D'Agostino GR, Frascino V, Dinapoli N, Mantini G, et al: Single-arm phase II study of conformal radiation therapy and temozolomide plus fractionated stereotactic conformal boost in high-grade gliomas: final report. Strahlenther Onkol 2010, 186(10):558-564.

9. Biswas T, Okunieff P, Schell MC, Smudzin T, Pilcher WH, Bakos RS, Vates GE, Walter KA, Wensel A, Korones DN, et al: Stereotactic radiosurgery for glioblastoma: retrospective analysis. Radiat Oncol 2009, 4:11.

10. Minniti G, Valeriani M, Clarke E, D'Arienzo M, Ciotti M, Montagnoli R, Saporetti F, Enrici RM: Fractionated stereotactic radiotherapy for skull base tumors: analysis of treatment accuracy using a stereotactic mask fixation system. Radiat Oncol 2010, 5:1.

11. Sikora M, Muzik J, Sohn M, Weinmann M, Alber M: Monte Carlo vs. pencil beam based optimization of stereotactic lung IMRT. Radiat Oncol 2009, 4:64.

12. Tanyi JA, Summers PA, McCracken $C L$, Chen Y, Ku LC, Fuss M: Implications of a high-definition multileaf collimator (HD-MLC) on treatment planning techniques for stereotactic body radiation therapy (SBRT): a planning study. Radiat Oncol 2009, 4:22

13. Wu QJ, Wang Z, Kirkpatrick JP, Chang Z, Meyer JJ, Lu M, Huntzinger C, Yin FF: Impact of collimator leaf width and treatment technique on stereotactic radiosurgery and radiotherapy plans for intra- and extracranial lesions. Radiat Oncol 2009, 4:3.

14. Yamashita H, Kobayashi-Shibata S, Terahara A, Okuma K, Haga A, Wakui R, Ohtomo K, Nakagawa K: Prescreening based on the presence of CT-scan abnormalities and biomarkers (KL-6 and SP-D) may reduce severe radiation pneumonitis after stereotactic radiotherapy. Radiat Oncol 5:32.

15. Kawaguchi K, Sato K, Horie A, Iketani S, Yamada H, Nakatani Y, Sato J, Hamada $Y$ : Stereotactic radiosurgery may contribute to overall survival for patients with recurrent head and neck carcinoma. Radiat Oncol 2010, 5:51. 
16. Gerszten PC, Burton SA, Ozhasoglu C, Welch WC: Radiosurgery for spinal metastases: clinical experience in 500 cases from a single institution. Spine (Phila Pa 1976) 2007, 32(2):193-199.

17. Chang EL, Shiu AS, Mendel E, Mathews LA, Mahajan A, Allen PK, Weinberg JS, Brown BW, Wang XS, Woo SY, et al: Phase I/II study of stereotactic body radiotherapy for spinal metastasis and its pattern of failure. J Neurosurg Spine 2007, 7(2):151-160.

18. Wowra B, Zausinger S, Drexler C, Kufeld M, Muacevic A, Staehler M, Tonn JC: CyberKnife radiosurgery for malignant spinal tumors: characterization of well-suited patients. Spine (Phila Pa 1976) 2008, 33(26):2929-2934.

19. Wowra B, Muacevic A, Zausinger S, Tonn JC: Radiosurgery for spinal malignant tumors. Dtsch Arztebl Int 2009, 106(7):106-112.

20. Sahgal A, Larson DA, Chang EL: Stereotactic body radiosurgery for spinal metastases: a critical review. Int I Radiat Oncol Biol Phys 2008, 71(3):652-665.

21. Lutz S, Berk L, Chang E, Chow E, Hahn C, Hoskin P, Howell D, Konski A, Kachnic L, Lo S, et al: Palliative radiotherapy for bone metastases: an ASTRO evidence-based guideline. Int I Radiat Oncol Biol Phys 79(4):965-976.

22. Chang EL, Shiu AS, Lii MF, Rhines LD, Mendel E, Mahajan A, Weinberg JS, Mathews $L A$, Brown BW, Maor MH, et al: Phase I clinical evaluation of near-simultaneous computed tomographic image-guided stereotactic body radiotherapy for spinal metastases. Int I Radiat Oncol Biol Phys 2004, 59(5):1288-1294.

23. Guckenberger M, Goebel J, Wilbert J, Baier K, Richter A, Sweeney RA, Bratengeier K, Flentje M: Clinical outcome of dose-escalated imageguided radiotherapy for spinal metastases. Int I Radiat Oncol Biol Phys 2009, 75(3):828-835.

24. Ryu S, Fang Yin F, Rock J, Zhu J, Chu A, Kagan E, Rogers L, Ajlouni M, Rosenblum M, Kim JH: Image-guided and intensity-modulated radiosurgery for patients with spinal metastasis. Cancer 2003, 97(8):2013-2018.

25. Garg AK, Wang XS, Shiu AS, Allen P, Yang J, McAleer MF, Azeem S, Rhines LD, Chang EL: Prospective evaluation of spinal reirradiation by using stereotactic body radiation therapy: The University of Texas MD Anderson Cancer Center experience. Cancer 2011, 117(15):3509-3516.

26. Gibbs IC, Patil C, Gerszten PC, Adler JR Jr, Burton SA: Delayed radiationinduced myelopathy after spinal radiosurgery. Neurosurgery 2009, 64(2 Suppl):A67-72

27. Kirkpatrick JP, van der Kogel AJ, Schultheiss TE: Radiation dose-volume effects in the spinal cord. Int J Radiat Oncol Biol Phys 2010, 76(3 Suppl): S42-49.

28. Sahgal A, Ma L, Gibbs I, Gerszten PC, Ryu S, Soltys S, Weinberg V, Wong S, Chang E, Fowler J, et al: Spinal cord tolerance for stereotactic body radiotherapy. Int J Radiat Oncol Biol Phys 2009, 77(2):548-553.

29. Ryu S, Jin JY, Jin R, Rock J, Ajlouni M, Movsas B, Rosenblum M, Kim JH: Partial volume tolerance of the spinal cord and complications of singledose radiosurgery. Cancer 2007, 109(3):628-636.

30. Sahgal A, Ames C, Chou D, Ma L, Huang K, Xu W, Chin C, Weinberg V, Chuang $C$, Weinstein $P$, et al: Stereotactic body radiotherapy is effective salvage therapy for patients with prior radiation of spinal metastases. Int J Radiat Oncol Biol Phys 2009, 74(3):723-731.

31. Choi CY, Adler JR, Gibbs IC, Chang SD, Jackson PS, Minn AY, Lieberson RE, Soltys SG: Stereotactic radiosurgery for treatment of spinal metastases recurring in close proximity to previously irradiated spinal cord. Int J Radiat Oncol Biol Phys 2010, 78(2):499-506.

32. Ang KK, Jiang GL, Feng Y, Stephens LC, Tucker SL, Price RE: Extent and kinetics of recovery of occult spinal cord injury. Int I Radiat Oncol Biol Phys 2001, 50(4):1013-1020.

33. Rades D, Veninga T, Stalpers LJ, Basic H, Rudat V, Karstens JH, Dunst J, Schild SE: Outcome after radiotherapy alone for metastatic spinal cord compression in patients with oligometastases. J Clin Oncol 2007, 25(1):50-56

34. Rose PS, Laufer I, Boland PJ, Hanover A, Bilsky MH, Yamada J, Lis E: Risk of fracture after single fraction image-guided intensity-modulated radiation therapy to spinal metastases. J Clin Oncol 2009, 27(30):5075-5079.

doi:10.1186/1748-717X-6-173

Cite this article as: Nikolajek et al: Spinal radiosurgery - efficacy and safety after prior conventional radiotherapy. Radiation Oncology 2011 6:173.

\section{Submit your next manuscript to BioMed Central and take full advantage of:}

- Convenient online submission

- Thorough peer review

- No space constraints or color figure charges

- Immediate publication on acceptance

- Inclusion in PubMed, CAS, Scopus and Google Scholar

- Research which is freely available for redistribution

Submit your manuscript at www.biomedcentral.com/submit
Biomed Central 